\title{
Removal of Crystal Violet Dye from Aqueous Solutions onto Date Palm Fiber by Adsorption Technique
}

\author{
Mashael Alshabanat, Ghadah Alsenani, and Rasmiah Almufarij \\ Chemistry Department, Science College, Princess Nora Bint Abdulrahman University, Riyadh, Saudi Arabia \\ Correspondence should be addressed to Mashael Alshabanat; ma.naif@hotmail.com
}

Received 29 October 2012; Revised 21 February 2013; Accepted 7 March 2013

Academic Editor: Ahmed El-Shafei

Copyright ( 2013 Mashael Alshabanat et al. This is an open access article distributed under the Creative Commons Attribution License, which permits unrestricted use, distribution, and reproduction in any medium, provided the original work is properly cited.

\begin{abstract}
The adsorption of crystal violet (CV) onto date palm fibers (DPFs) was examined in aqueous solution at $25^{\circ} \mathrm{C}$. The experimental maximum adsorption capacity value was $0.66 \times 10^{-6}$. Langmuir, Freundlich, Elovich and Temkin models were applied to describe the equilibrium isotherms. The influence of $\mathrm{pH}$ and temperature on dye removal was evaluated. The percentage removal of $\mathrm{CV}$ dye by adsorption onto DPF at different $\mathrm{pH}$ and temperatures showed that these factors play a role in the adsorption process. Thermodynamic analysis was performed, and the Gibbs free energy $\Delta G^{\circ}$, enthalpy change $\Delta H^{\circ}$, and entropy $\Delta S^{\circ}$ were calculated. The negative values of $\Delta G^{\circ}$ indicate spontaneous adsorption. The negative value of $\Delta H^{\circ}$ indicates that the interaction between $\mathrm{CV}$ and DPF is exothermic, and the positive value of $\Delta S^{\circ}$ indicates good affinity between DPF and CV. The kinetic data were fitted to a pseudo-second-order model.
\end{abstract}

\section{Introduction}

Adsorption using different adsorbents is superior to the other separation techniques because of its efficacy, economy, ability to separate a wide range of chemical compounds, and simple procedure. Research in the past few years has focused on utilizing waste materials from agricultural products because they are inexpensive, ecofriendly, and renewable. Several materials have been studied as potential adsorbents, such as orange peels [1], mango seed husks [2], pineapple stems [3], coconut bunch waste [4], pumpkin seeds [5], and cotton plant waste [6]. Wastewater from dyeing and finishing operations in the textile industry is generally high in both color and organic content. Effluents discharged from dyeing industries are highly colored and can be toxic to aquatic life in the receiving waters $[7,8]$. Color removal from textile effluents has received attention due to its visibility even more than its potential toxicity $[9,10]$. Saudi Arabia is among the developing countries with a need to establish new industries based on utilizing natural resources in various sectors. Date palm is an important fruit crop of Saudi Arabia and occupies a large percentage of the cultivated land. Thus, using date palm waste to develop new adsorbents for the wastewater treatment by adsorption is quite attractive.
This work studies the removal of CV dye by adsorption using date palm fiber (DPF). The effect of $\mathrm{pH}$ and temperature and the thermodynamic parameters are also evaluated. Finally, the adsorption kinetics are investigated.

\section{Materials and Methods}

The date palm fiber (DPF) used for the preparation of the adsorbent was obtained locally from a farm in the southern region of Riyadh City in Saudi Arabia. The material was sorted, cut, crushed, grinded, and sieved to obtain fine particles. Crystal violet (CV) was supplied by Techno PharmChem, Bahadurgarh (India). The dye content is at least $88 \%$. Distilled water was used to prepare solutions at the desired concentrations by diluting the stock solution. For each individual test, $0.25 \mathrm{~g}$ samples of the adsorbent were placed into screw-capped Erlenmeyer flasks containing $25 \mathrm{~mL}$ of $\mathrm{CV}$ solution at different concentrations, from $0.9 \times 10^{-5}$ to $7 \times 10^{-5} \mathrm{~mol} / \mathrm{L}$. The flasks were shaken for a sufficient period to achieve equilibrium using an orbital shaker (J. P. Selecta, Spain) at $100 \mathrm{rpm}$ and $25^{\circ} \mathrm{C}$. The mixture solution was filtered using Whatman filter paper $(125 \mathrm{~mm} \varnothing$, Cat. no. 1001 125). The dye uptake was monitored spectrophotometrically by measuring the absorbance at $\lambda_{\max } 584 \mathrm{~nm}$. The amount 


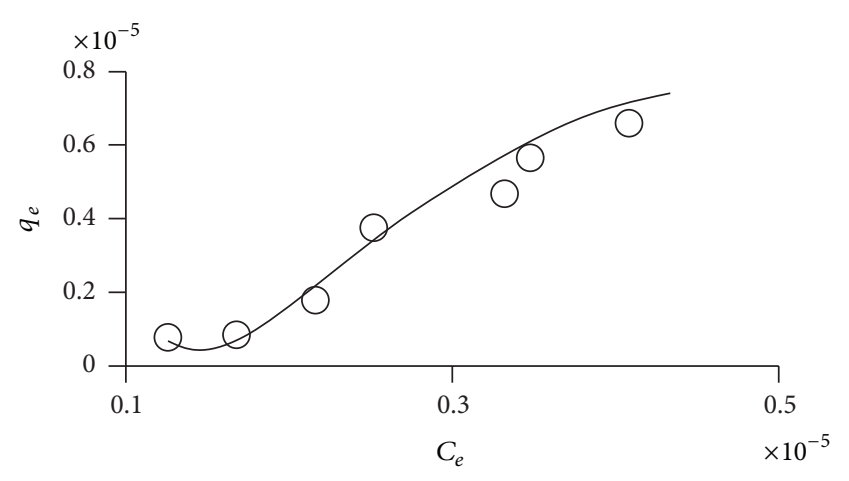

FIGURE 1: Adsorption isotherm of CV onto DPF (experimental conditions: $25^{\circ} \mathrm{C}, 100 \mathrm{rpm}, \lambda_{\max }$ of absorbance $=584 \mathrm{~nm}$, and adsorbent mass $=0.25 \mathrm{gm}$ per $25 \mathrm{~mL}$ of CV solution at different concentrations: $\left.0.9 \times 10^{-5}-7 \times 10^{-5}\right)$.

of adsorption at equilibrium, $q_{e}(\mathrm{~mol} / \mathrm{g})$, was calculated by

$$
q_{e}=\frac{\left(C_{0}-C_{e}\right) V}{m},
$$

where $C_{0}$ and $C_{e}(\mathrm{~mol} / \mathrm{L})$ are the liquid-phase dye concentrations initially and at equilibrium, respectively, $V$ is the volume of the solution (L), and $m$ is the mass of dry adsorbent $(\mathrm{g})$. The equilibrium data were then fitted using four different isotherm models, namely, the Langmuir, Freundlich, Elovich, and Temkin models.

The percentage removal was studied as a function of $\mathrm{pH}$. The effect of $\mathrm{pH}$ on the adsorption process was studied by preparing adsorbent-adsorbate solutions with fixed adsorbent dose $(0.25 \mathrm{gm})$ and dye concentration $\left(3 \times 10^{-5}\right)$ but different $\mathrm{pH}$ by adding $\mathrm{NaOH}(1 \mathrm{M})$ or $\mathrm{HCl}(1 \mathrm{M})$ solutions and shaking until equilibrium.

The temperature dependence of CV sorption onto DPF was studied with a constant initial concentration at $100 \mathrm{rpm}$. The percentage removal at $25,35,45$, and $55^{\circ} \mathrm{C}$ was recorded. The thermodynamic parameters $\Delta G^{\circ}, \Delta H^{\circ}$, and $\Delta S^{\circ}$ were calculated.

The kinetic study was also performed with a flask shaken only for the desired time period.

\section{Results and Discussion}

3.1. Adsorption Isotherms. The adsorption isotherm indicates how the adsorption molecules are distributed between the liquid phase and the solid phase when the adsorption process is at equilibrium [11]. The adsorption isotherm of CV onto DPF is illustrated in Figure 1. This isotherm is classified as type $S$ according to the Giles et al. classification, indicating that adsorption becomes easier for increasing concentration. The $S$ curve of the adsorption isotherm generally reflects strong competition between the solvent and the adsorbed species for the adsorbent surface sites [12]. From Figure 1, the experimental maximum adsorption capacity for the dye onto DPF is approximately $0.66 \times 10^{-6} \mathrm{~mol} \mathrm{~g}^{-1}$.

The fitting of the isotherm data to different models is an important step for finding a suitable model that can be used for design purposes [13]. Linear forms of the Langmuir, Freundlich, Elovich, and Temkin adsorption isotherm models $((2),(3),(4)$, and (5), resp.) were used to verify the sorption data:

$$
\begin{gathered}
\frac{1}{q_{e}}=\frac{1}{Q_{0}}+\left(\frac{1}{b Q_{0}}\right)\left(\frac{1}{C_{e}}\right), \\
\log q_{e}=\log K_{f}+\frac{1}{n} \log C_{e}, \\
\ln \frac{q_{e}}{C_{e}}=\ln K_{E} Q_{0}-\frac{q_{e}}{\widehat{Q}_{0}}, \\
q_{e}=B \ln A+B \ln C_{e},
\end{gathered}
$$

where $C_{e}$ is the equilibrium concentration, $q_{e}$ is the amount of adsorbate adsorbed per unit mass of adsorbent, $Q_{0}$ is the maximum adsorption capacity, $b$ is the Langmuir constant related to the adsorption rate, $K_{f}$ is the Freundlich isotherm constant related to adsorption capacity (indicating the quantity of dye adsorbed onto the adsorbent), $n$ is the Freundlich isotherm constant related to adsorption intensity (indicating the favorability of the adsorption process), $K_{E}$ is the Elovich equilibrium constant, and $B$ and $A$ are constants related to the heat of adsorption and the equilibrium binding constant, respectively, $B=R T / b$, where $R$ is the constant gas, $T(\mathrm{~K})$ is the absolute temperature, and $b$ is the Temkin isotherm constant.

The Langmuir [14] model assumes uniform energies of adsorption onto the surface and no transmigration of the adsorbate along the plane of the surface. A linear fit to the Langmuir equation yields Langmuir constant $(b)$ and the maximum adsorption capacity $\left(\mathbb{Q}_{0}\right)$ from the slopes and the intercepts, respectively.

The Freundlich model assumes that as the adsorbate concentration increases, the concentration of adsorbate on the adsorbent surface also increases. The linear form of the Freundlich isotherm model yields a straight line. The slope and intercept of the obtained fit are used to calculate the Freundlich constants $n$ and $K_{f}$ [15]. The Elovich model [16] is based on a kinetic principle assuming that the adsorption sites increase exponentially with adsorption, which implies a multilayer adsorption. The Elovich maximum adsorption capacity and Elovich constant can be calculated from the slopes and the intercepts of the plot of $\ln \left(q_{e} / C_{e}\right)$ versus $q_{e}$. The Temkin [17] isotherm equation assumes that the heat of adsorption of all the molecules in the layer decreases linearly with coverage due to adsorbent-adsorbate interactions and that the adsorption is characterized by a uniform distribution of the binding energies up to some maximum binding energy. The Temkin equilibrium constants can be calculated from the slope and intercept of the plot of $q_{e}$ versus $\ln C_{e}$. However, all the constants of these models are given in Table 1.

The applicability of the isotherm equations to describe the adsorption process was judged based on the maximum value of adsorption and correlation coefficients $\left(R^{2}\right)$, which are a measure of goodness of fit.

For Langmuir, the maximum value of adsorption $\left(\mathbb{Q}_{0}\right)$ is negative and this observation reflects the inadequacy of this model for explaining the adsorption process, although 
TABLE 1: Isotherm model constants for the adsorption of CV onto DPF.

\begin{tabular}{lccc}
\hline Isotherm & \multicolumn{1}{c}{ Constants } & $R^{2}$ & $Q_{\text {Experimental }} \times 10^{-6} \mathrm{~mol} \mathrm{~g}^{-1}$ \\
\hline \multirow{2}{*}{ Langmuir } & $Q_{0} \times 10^{-4}\left(\mathrm{~mol} \mathrm{~g}^{-1}\right)$ & $b \times 10^{-5}\left(\mathrm{~L} \mathrm{~mol}^{-1}\right)$ & 0.996 \\
Freundlich & -0.2396 & 1.1137 & \\
& $n$ & $K_{f} \times 10^{4}(\mathrm{~L} / \mathrm{g})$ & 0.989 \\
Elovich & 0.524 & 13.1825 & \\
& $Q_{0} \times 10^{-6}\left(\mathrm{~mol} \mathrm{~g}^{-1}\right)$ & $K_{E} \times 10^{4}\left(\mathrm{~L} \mathrm{~mol}^{-1}\right)$ & 0.961 \\
Temkin & 0.579 & 2.9845 & \\
& $A \times 10^{5}\left(\mathrm{~mol} \mathrm{~g}^{-1}\right)$ & $B \times 10^{-5}$ & 0.916 \\
\hline
\end{tabular}

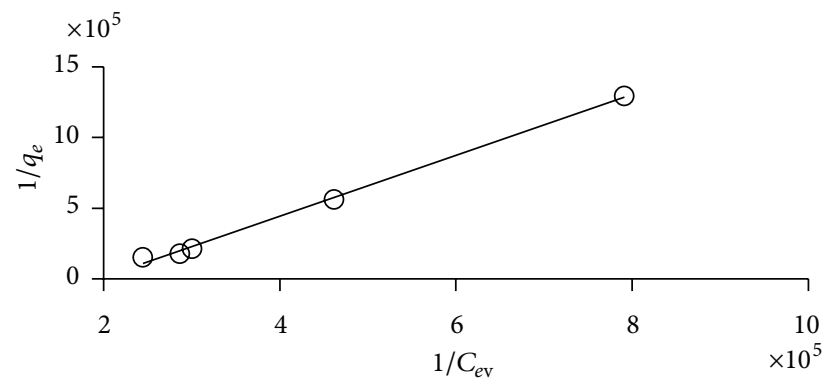

FIGURE 2: Langmuir plot of CV onto DPF (experimental conditions: $25^{\circ} \mathrm{C}, 100 \mathrm{rpm}, \lambda_{\max }$ of absorbance $=584 \mathrm{~nm}$, and adsorbent mass $=0.25 \mathrm{gm}$ per $25 \mathrm{~mL}$ of $\mathrm{CV}$ solution at different concentrations: 0.9 $\left.\times 10^{-5}-7 \times 10^{-5}\right)$.

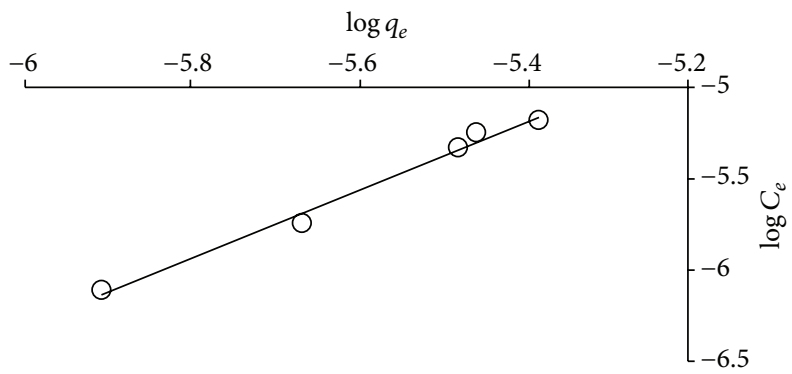

FIGURE 3: Freundlich plot of CV onto DPF (experimental conditions: $25^{\circ} \mathrm{C}, 100 \mathrm{rpm}, \lambda_{\max }$ of absorbance $=584 \mathrm{~nm}$, and adsorbent mass $=0.25$ gm per $25 \mathrm{~mL}$ of CV solution at different concentrations: $\left.0.9 \times 10^{-5}-7 \times 10^{-5}\right)$.

it shows a good linearity compared to other models (see Figure 2 and Table 1).

For Freundlich model, the maximum adsorption capacity obtained using the equation is higher than the experimental value, indicating that the experimental adsorption data does not fit this model, although the high $R^{2}$ value it takes (see Figure 3 and Table 1).

The adsorption capacity determined using the linear transformation of the Elovich equation $\left(=0.579 \times 10^{-6}\right)$ is approximately equal to the experimental measurements at equilibrium, corresponding to the plateau of the adsorption isotherms $\left(=0.66 \times 10^{-6}\right)$. Thus, the assumption of exponential covering of adsorption sites, which implies multilayer

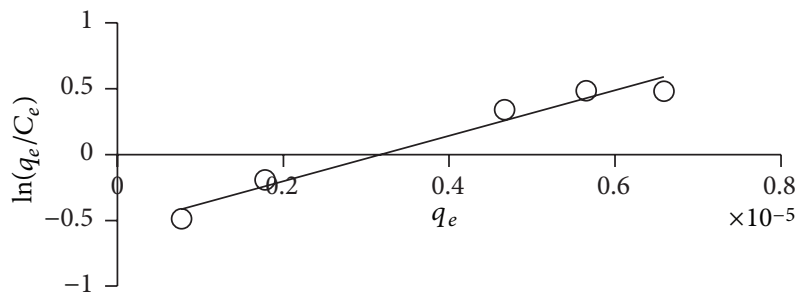

FIgURE 4: Elovich plot of CV onto DPF (experimental conditions: $25^{\circ} \mathrm{C}, 100 \mathrm{rpm}, \lambda_{\max }$ of absorbance $=584 \mathrm{~nm}$, and adsorbent mass $=0.25 \mathrm{gm}$ per $25 \mathrm{~mL}$ of $\mathrm{CV}$ solution at different concentrations: 0.9 $\left.\times 10^{-5}-7 \times 10^{-5}\right)$.

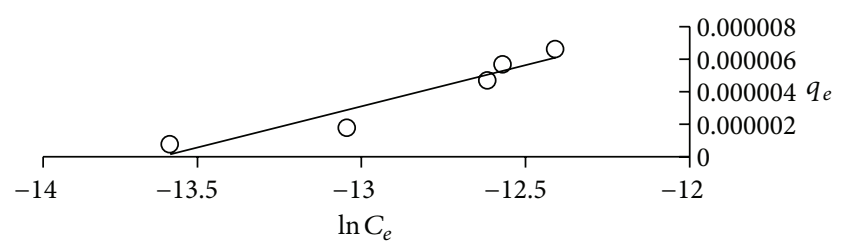

FIgURE 5: Temkin plot of CV onto DPF (experimental conditions: $25^{\circ} \mathrm{C}, 100 \mathrm{rpm}, \lambda_{\max }$ of absorbance $=584 \mathrm{~nm}$, and adsorbent mass $=0.25 \mathrm{gm}$ per $25 \mathrm{~mL}$ of CV solution at different concentrations: 0.9 $\left.\times 10^{-5}-7 \times 10^{-5}\right)$.

adsorption, is in agreement with the experimental results in the studied concentration range. Regarding the $R^{2}$ value, this model also shows good linearity, with $R^{2}$ is close to unity, see Figure 4 and Table 1.

For the Temkin isotherm, The value of $R^{2}$ is the lowest of all studied models. Thus, this model describes the adsorption isotherm of CV onto DPF poorly, see Figure 5 and Table 1.

Thus, it can be said that the experimental adsorption data fit the Elovich model was fairly well compared to the other models based on the maximum value of adsorption and correlation coefficients $\left(R^{2}\right)$.

3.2. Effect of $p H$. Acidity is very important in the adsorption process, especially for dye adsorption. The $\mathrm{pH}$ of a medium will control the magnitude of the electrostatic charges imparted by the ionized dye molecules. Both the adsorbent and adsorbate may have functional groups that can be protonated or deprotonated to produce different surface charges in solutions at different $\mathrm{pH}$, resulting in electrostatic 


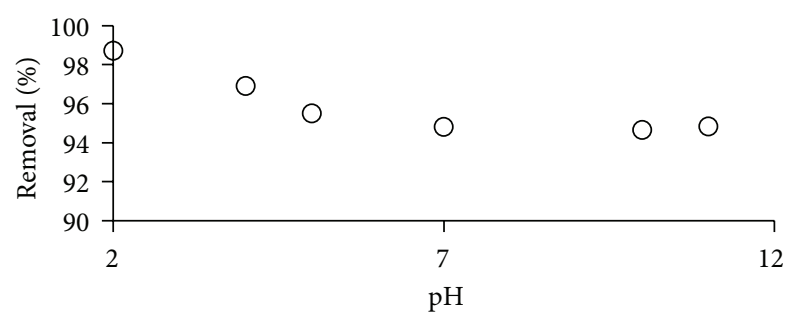

Figure 6: Percentage removal of CV dye onto DPF at different $\mathrm{pH}$ values (experimental conditions: $25^{\circ} \mathrm{C}, 100 \mathrm{rpm}, \lambda_{\max }$ of absorbance $=584 \mathrm{~nm}$, and adsorbent mass $=0.25 \mathrm{gm}$, and dye concentration $=3$ $\left.\times 10^{-5}\right)$.

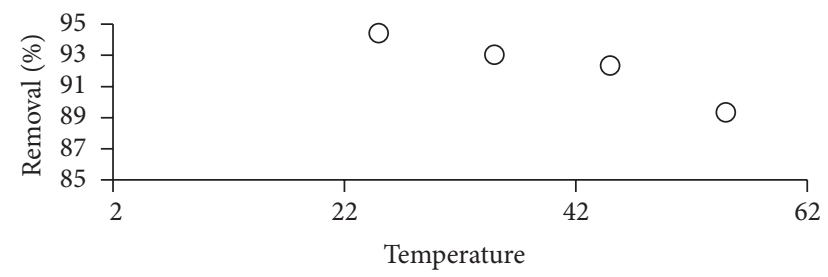

Figure 7: Percentage removal of CV dye onto DPF at different temperatures (experimental conditions: $25,35,45$, and $55^{\circ} \mathrm{C}, 100 \mathrm{rpm}$, $\lambda_{\max }$ of absorbance $=584 \mathrm{~nm}$, and adsorbent mass $=0.25 \mathrm{gm}$ ).

attraction or repulsion between the charged adsorbates and adsorbents [18]. Therefore, the effect of $\mathrm{pH}$ on the adsorption behavior of the dye on the adsorbent was studied by observing the percentage of dye removal over a wide $\mathrm{pH}$ range of 211. The variation in the removal of $\mathrm{CV}$ with $\mathrm{pH}$ is shown in Figure 6. As presented in the figure, the obtained results show that the percentage removal of dye decreases slightly with increasing basicity up to $\mathrm{pH} 7.0$, after which it remains almost constant. This behavior may be due to the increase in negative charge density of surface at acidic $\mathrm{pH}$, resulting in a attraction between the positively charged dye molecule and adsorbent. As the $\mathrm{pH}$ increases, the surface charge density on the adsorbent decreases, resulting in electrostatic repulsion from the positive charge of the dye molecule.

3.3. Effect of Temperature. The effect of temperature on the sorption of CV by DPF is shown in Figure 7. The percentage of dye removal decreases from $94 \%$ to $89 \%$ for dye as the solution temperature increases from 25 to $55^{\circ} \mathrm{C}$. Because the adsorption decreased as the temperature increased, the system is considered to be exothermic. A similar trend was reported by Chandra et al. [19] for the adsorption of $\mathrm{MB}$ on activated carbon prepared from durian shell, who explained that as the temperature increased, the physical bonding between the organic compound (including the dye) and the active sites of the adsorbent weakened. In addition, the dye solubility also increased, which caused the interaction between the solute and solvent to become stronger than that between the solute and adsorbent. Therefore, the solute was more difficult to adsorb.

3.4. Thermodynamic Parameters. The thermodynamic parameters for the adsorption of CV on DPF were calculated using

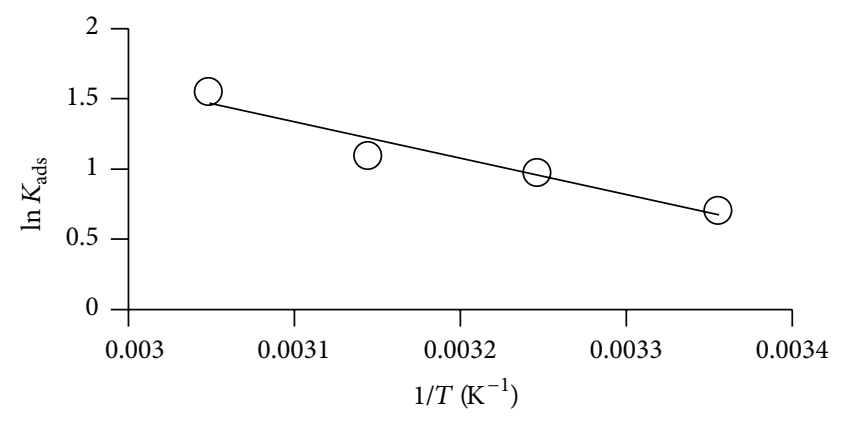

Figure 8: $\ln K_{\text {ads }}$ versus $1 / T$ according to the van't Hoff equation (7) (experimental conditions: $25,35,45$, and $55^{\circ} \mathrm{C}, 100 \mathrm{rpm}, \lambda_{\max }$ of absorbance $=584 \mathrm{~nm}$, and adsorbent mass $=0.25 \mathrm{gm}$ ).

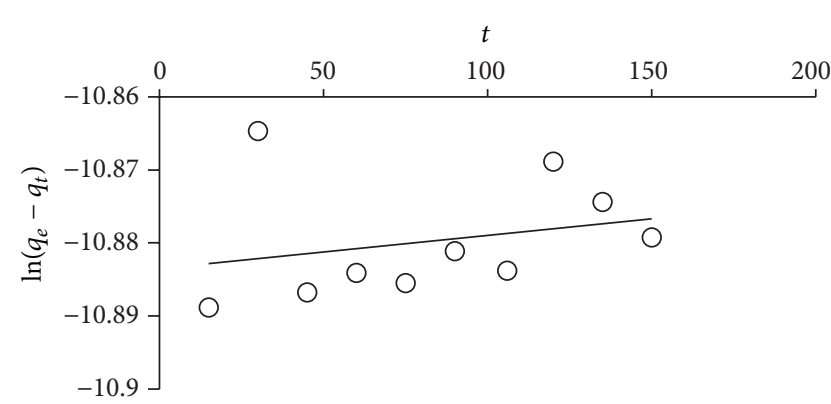

FIGURE 9: $\ln \left(q_{e}-q_{t}\right)$ versus time ( $\mathrm{min}$ ) for the adsorption of $\mathrm{CV}$ onto DPF (experimental conditions: $25^{\circ} \mathrm{C}, 100 \mathrm{rpm}, \lambda_{\max }$ of absorbance $=584 \mathrm{~nm}$, and adsorbent mass $=0.25 \mathrm{gm}$, period time: $15,30,45,60$, $75,90,106,120,135$, and $150 \mathrm{~min})$.

the following equations, and the values are given in Table 2 (Figure 8 represents (7));

$$
\begin{gathered}
\Delta G^{\circ}=-R T \ln K_{\mathrm{ads}}, \\
\ln K_{\mathrm{ads}}=\frac{\Delta S^{\circ}}{R}-\frac{\Delta H^{\circ}}{R T} .
\end{gathered}
$$

The equilibrium constants $\left(K_{\mathrm{ads}}\right)$ were calculated according to the following equation [20]:

$$
K_{\mathrm{ads}}=\frac{\text { dye concentration on the solid at equilibrium }}{\text { dye concentrati in solution at equilibrium }} \text {, }
$$

where $\Delta G^{\circ}, \Delta H^{\circ}$ and $\Delta S^{\circ}$ are the changes in Gibb's free energy, enthalpy, and entropy, respectively. The negative free energy value at $25^{\circ} \mathrm{C}$ indicates the feasibility of the process and its spontaneous nature. The exothermic nature of process was confirmed by the negative value of enthalpy change $\Delta H^{\circ}$. The positive entropy change $\Delta S^{\circ}$ indicates the good affinity of DPF for CV and the increasing disorder at the solid-solution interface during the adsorption process.

3.5. Kinetic Study. The study of adsorption kinetics describes the solute uptake rate, which controls the residence time of the adsorbate at the solid/solution interface. The kinetics of 


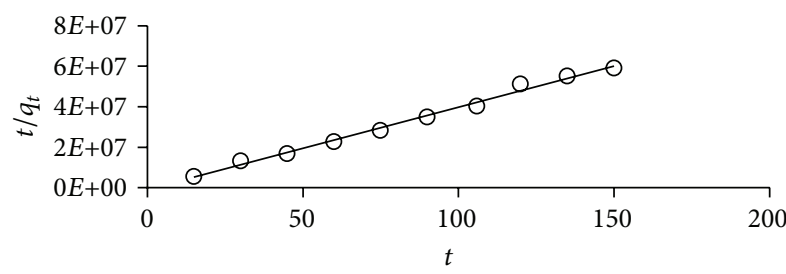

FIgURE 10: $t / q_{t}$ versus time ( $\mathrm{min}$ ) for the adsorption of $\mathrm{CV}$ onto DPF (experimental conditions: $25^{\circ} \mathrm{C}, 100 \mathrm{rpm}, \lambda_{\max }$ of absorbance $=584 \mathrm{~nm}$, and adsorbent mass $=0.25 \mathrm{gm}$, period of time: $15,30,45$, $60,75,90,106,120,135$, and $150 \mathrm{~min}$ ).

TABLE 2: Thermodynamic parameters for the adsorption of CV onto DPF.

\begin{tabular}{cccc}
\hline $25^{\circ} \mathrm{C}(298 \mathrm{~K})$ & $\Delta G^{\circ}(\mathrm{kJ} / \mathrm{mol})$ & $\Delta H^{\circ}(\mathrm{kJ} / \mathrm{mol})$ & $\Delta S^{\circ}(\mathrm{J} / \mathrm{mol} \mathrm{K})$ \\
& -1.73926 & -21.516632 & 77.7941 \\
\hline
\end{tabular}

TABLE 3: Rate constant and adsorption capacity at equilibrium for the adsorption of CV onto DPF.

\begin{tabular}{|c|c|c|c|}
\hline The order & Consta & & $R^{2}$ \\
\hline 2nd & $\begin{array}{c}K_{2} \times 10^{3}\left(\mathrm{~g} \mathrm{~mol}^{-1} \mathrm{~min}^{-1}\right) \\
20.132\end{array}$ & $\begin{array}{c}q_{e} \times 10^{-6}(\mathrm{~mol} / \mathrm{g}) \\
0.86\end{array}$ & 0.999 \\
\hline
\end{tabular}

CV adsorption onto DPF were analyzed using pseudo-firstorder and pseudo-second-order kinetic models. The linear pseudo-first-order equation [21] is given as follows:

$$
\ln \left(q_{e}-q_{t}\right)=\ln q_{e}-K_{1} t
$$

where $q_{e}$ and $q_{t}$ are the amount adsorbed at equilibrium and at time $t$, respectively, and $\left(K_{1}\right)$ is the rate constant of the pseudo-first-order adsorption. A plot of $\ln \left(q_{e}-q_{t}\right)$ versus $t$ (see Figure 9) should be linear, and rate constant $\left(K_{1}\right)$ and adsorption capacity at equilibrium $\left(q_{e}\right)$ can be determined from the slope and intercept of the plot, respectively. The value of $R^{2}(=0.067)$ indicates that the first-order Lagergren equation did not fit the complete range of the adsorption process well. follows:

The linear pseudo-second-order equation [22] is given as

$$
\frac{t}{q_{t}}=\frac{1}{K_{2} q_{e}^{2}}+\frac{1}{q_{e}} t
$$

where $\left(K_{2}\right)$ is the pseudo-second-order rate constant. The slope of the plot of $t / q_{t}$ versus $t$ gives the value of $q_{e}$, and the intercept can be used to calculate $\left(K_{2}\right)$. The plot of $t / q_{t}$ versus $t$ (see Figure 10) yields a very straight line. The correlation coefficient $\left(R^{2}\right)$ for this model is 0.992 , indicating a better fit for the former. The calculated and experimental $q_{e}$ values agreed satisfactorily. However, the calculated, $q_{e}$, and the rate constant, $\left(K_{2}\right)$, are given in Table 3.

\section{Conclusions}

This study indicates that date palm fiber (DPF) is a promising adsorbent for the removal of crystal violet dye (CV) from aqueous solutions over a range of concentrations. Equilibrium data were analyzed according to Langmuir, Freundlich, Elovich, and Temkin isotherms. Despite the much higher correlation coefficient for the Langmuir and Freundlich models, the Elovich model was best able to describe the adsorption isotherm of CV onto DPF because the maximum adsorption capacity obtained from this model was equal to the experimental value. The temperature and $\mathrm{pH}$ play a role in the adsorption process. Greater adsorption occurred at low temperature and $\mathrm{pH}$. The thermodynamic calculations indicated that the process was spontaneous and exothermic. The kinetics analysis revealed that the pseudo-second-order model was a better fit of the experimental data than the firstorder kinetic expressions.

\section{Acknowledgment}

The authors would like to thank the Deanship of Scientific Research at Princess Nora University for providing the funding for this work under project number 016-5-31.

\section{References}

[1] A. Khaled, A. El Nemr, A. El-Sikaily, and O. Abdelwahab, "Treatment of artificial textile dye effluent containing Direct Yellow 12 by orange peel carbon," Desalination, vol. 238, no. 1-3, pp. 210-232, 2009.

[2] M. M. Dávila-Jiménez, M. P. Elizalde-González, and V. Hernández-Montoya, "Performance of mango seed adsorbents in the adsorption of anthraquinone and azo acid dyes in single and binary aqueous solutions," Bioresource Technology, vol. 100, no. 24, pp. 6199-6206, 2009.

[3] B. H. Hameed, R. R. Krishni, and S. A. Sata, "A novel agricultural waste adsorbent for the removal of cationic dye from aqueous solutions," Journal of Hazardous Materials, vol. 162, no. 1, pp. 305-311, 2009.

[4] B. H. Hameed, D. K. Mahmoud, and A. L. Ahmad, "Equilibrium modeling and kinetic studies on the adsorption of basic dye by a low-cost adsorbent: coconut (Cocos nucifera) bunch waste," Journal of Hazardous Materials, vol. 158, no. 1, pp. 65-72, 2008.

[5] B. H. Hameed and M. I. El-Khaiary, "Removal of basic dye from aqueous medium using a novel agricultural waste material: pumpkin seed hull," Journal of Hazardous Materials, vol. 155, no. 3, pp. 601-609, 2008.

[6] Ö. Z. Tunc, H. Tanac1, and Z. Aksu, "Potential use of cotton plant wastes for the removal of remazol black B reactive dye," Journal of Hazardous Materials, vol. 163, no. 1, pp. 187-198, 2009.

[7] C. K. Lee, K. S. Low, and P. Y. Gan, "Removal of some organic dyes by acid-treated spent bleaching earth," Environmental Technology, vol. 20, no. 1, pp. 99-104, 1999.

[8] K. Kadirvelu, M. Kavipriya, C. Karthika, M. Radhika, N. Vennilamani, and S. Pattabhi, "Utilization of various agricultural wastes for activated carbon preparation and application for the removal of dyes and metal ions from aqueous solutions," Bioresource Technology, vol. 87, no. 1, pp. 129-132, 2003.

[9] R. Y. L. Yeh and A. Thomas, "Color difference measurement and color removal from dye wastewaters using different adsorbents," Journal of Chemical Technology and Biotechnology, vol. 63, no. 1, pp. 55-59, 1995. 
[10] L. C. Morais, O. M. Freitas, E. P. Gancolves, L. T. Vaskancelos, and C. G. Gonzalez Beca, "Reactive dyes removal from wastewaters by adsorption on eucalyptus bark: variables that define the process," Water Research, vol. 33, no. 4, pp. 979-988, 1999.

[11] I. A. W. Tan, A. L. Ahmad, and B. H. Hameed, "Adsorption of basic dye on high-surface-area activated carbon prepared from coconut husk: equilibrium, kinetic and thermodynamic studies," Journal of Hazardous Materials, vol. 154, no. 1-3, pp. 337346, 2008.

[12] C. H. Giles, T. H. MacEwan, S. N. Nakhwa, and D. Smith, “786. Studies in adsorption. Part XI. A system of classification of solution adsorption isotherms, and its use in diagnosis of adsorption mechanisms and in measurement of specific surface areas of solids," Journal of the Chemical Society, pp. 3973-3993, 1960.

[13] M. S. El-Geundi, "Homogeneous surface diffusion model for the adsorption of basic dyestuffs onto natural clay in batch adsorbers," Adsorption Science and Technology, vol. 8, no. 4, pp. 217-225, 1991.

[14] I. Langmuir, "The constitution and fundamental properties of solids and liquids. Part I. Solids," The Journal of the American Chemical Society, vol. 38, no. 2, pp. 2221-2295, 1916.

[15] R. E. Treybal, Mass-Transfer Operation, McGraw-Hill, New York, NY, USA, 3rd edition, 1981.

[16] S. Y. Elovich and O. G. Larinov, "Theory of adsorption from solutions of nonelectrolytites on solid adsorbents (I) equation adsorption isotherm from solutions and the analysis of its simplest from, (II) verification of the equation of adsorption isotherm from solution," Izvestiya Akademii Nauk SSSR, vol. 2, pp. 209-216, 1962.

[17] M. I. Temkin, "Adsorption equilibrium and process kinetics on inhomogeneous surfaces with interaction between adsorbed molecules," Zhurnal Fizicheskoi Khimii, vol. 15, pp. 296-332, 1941.

[18] Z. Wu, H. Joo, and K. Lee, "Kinetics and thermodynamics of the organic dye adsorption on the mesoporous hybrid xerogel," Chemical Engineering Journal, vol. 112, no. 1-3, pp. 227-236, 2005.

[19] T. C. Chandra, M. M. Mirna, Y. Sudaryanto, and S. Ismadji, "Adsorption of basic dye onto activated carbon prepared from durian shell: studies of adsorption equilibrium and kinetics," Chemical Engineering Journal, vol. 127, no. 1-3, pp. 121-129, 2007.

[20] Y. Yu, Y. Yi Zhuang, and Z. H. Wang, "Adsorption of watersoluble dye onto functionalized resin," Journal of Colloid and Interface Science, vol. 242, no. 2, pp. 288-293, 2001.

[21] S. Lagergren, "About the theory of so called adsorption of soluble substances," Ksver Veterskapsakad Handl, vol. 24, pp. 1-6, 1898.

[22] Y. S. Ho and G. McKay, "Sorption of dye from aqueous solution by peat," Chemical Engineering Journal, vol. 70, no. 2, pp. 115$124,1998$. 

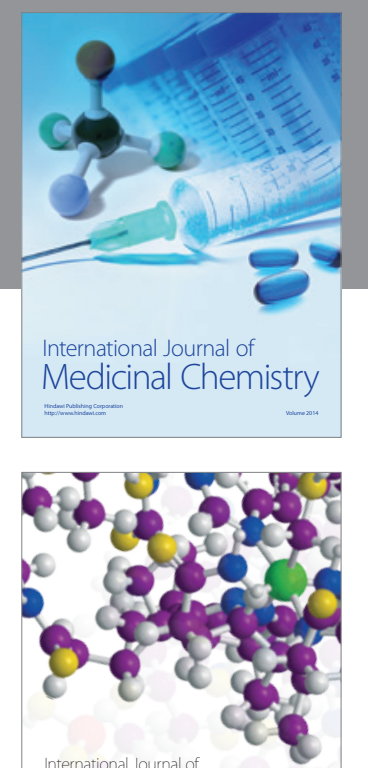

\section{Carbohydrate} Chemistry

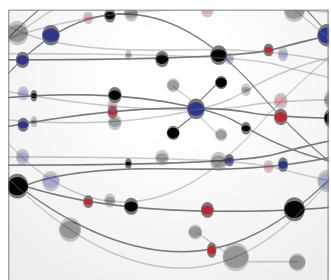

The Scientific World Journal
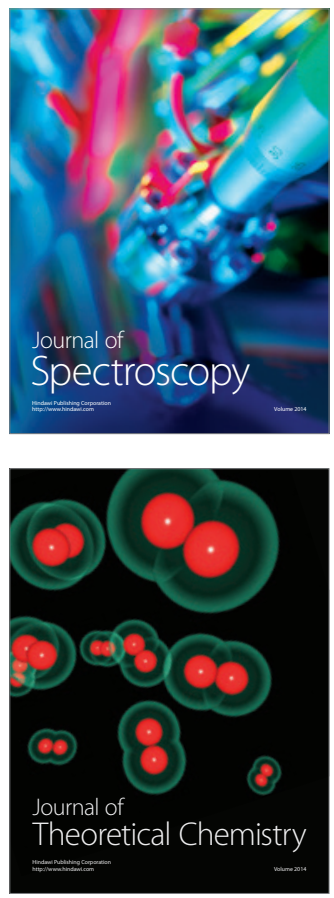
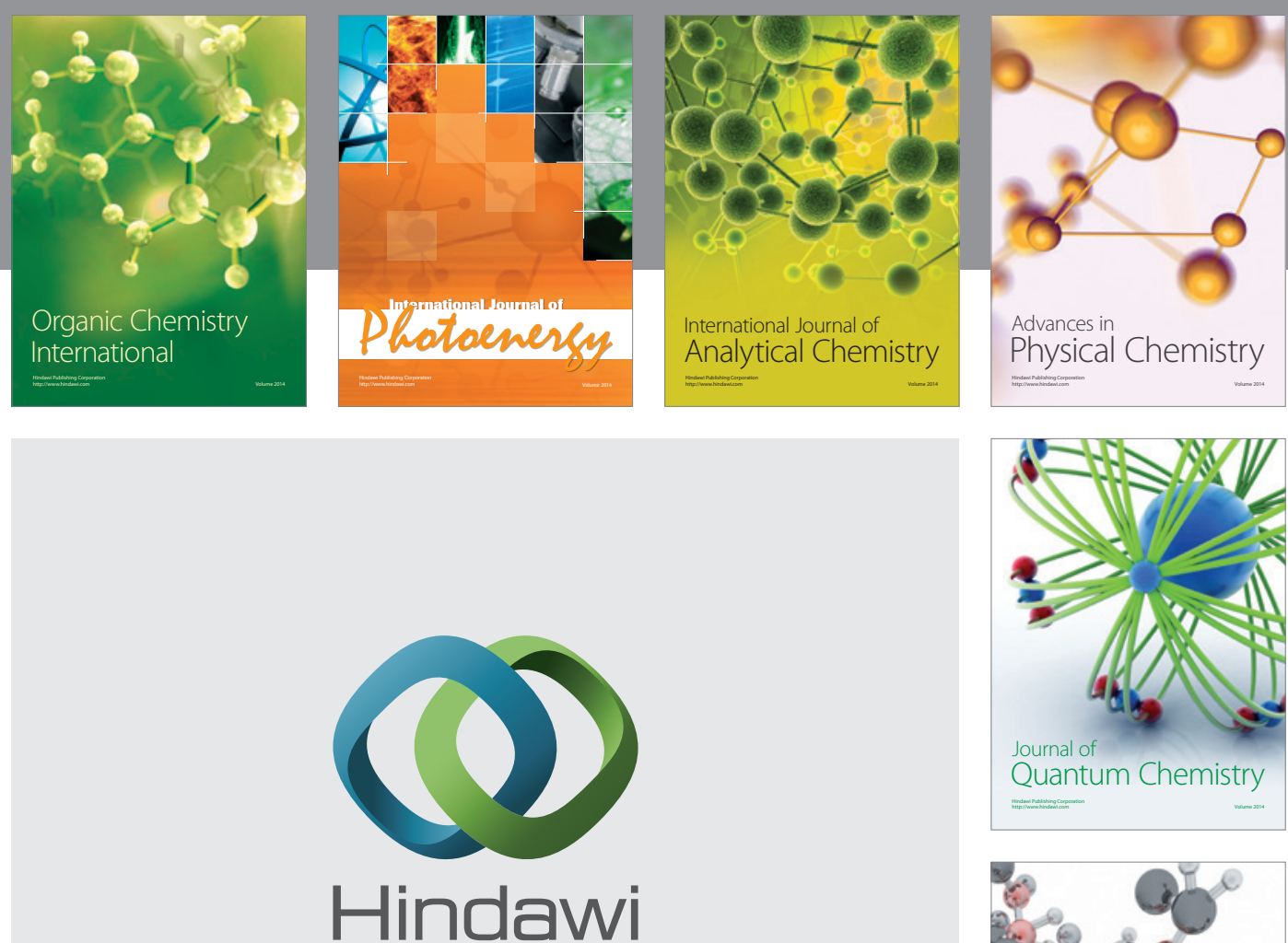

Submit your manuscripts at

http://www.hindawi.com

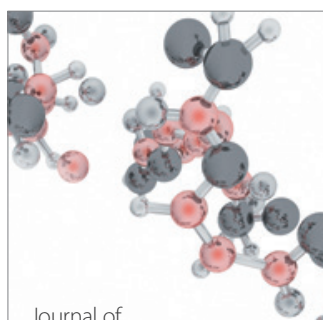

Analytical Methods

in Chemistry

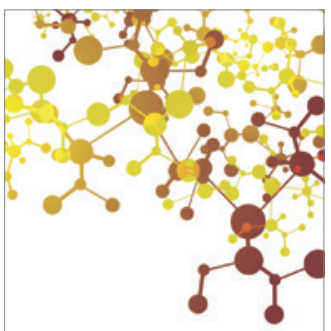

Journal of

Applied Chemistry

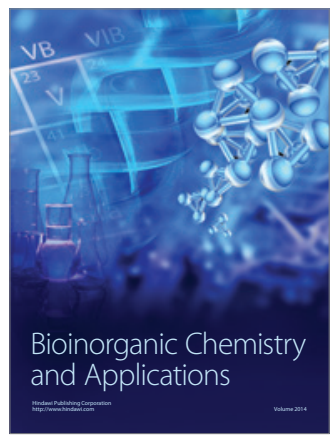

Inorganic Chemistry
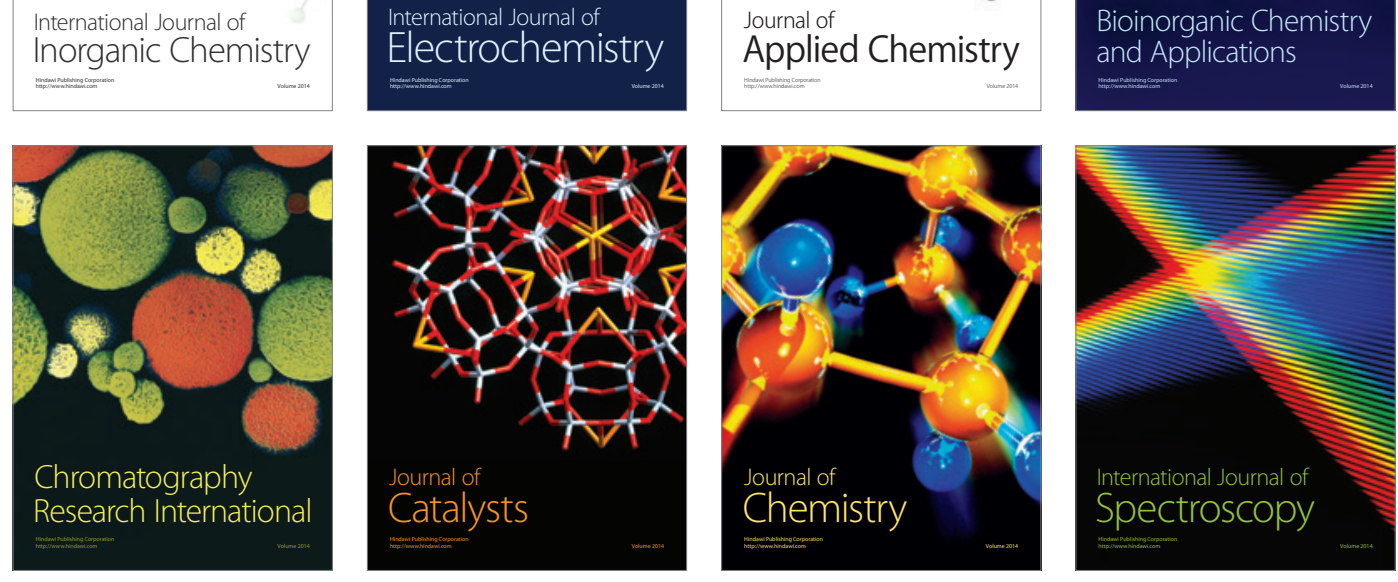